\title{
A fusion of research-informed teaching and teaching-informed research: Designing a scalable online ecosystem for new partnerships in educational research
}

\author{
Cornelia Connolly, Tony Hall \\ School of Education, National University of Ireland, Galway, Ireland
}

\author{
Marie Ryan \\ Mary Immaculate College, Limerick, Ireland
}

Jennifer McMahon

University of Limerick, Ireland

\section{Marek McGann}

Mary Immaculate College, Limerick, Ireland

\author{
Alison Egan \\ Marino Institute of Education, Ireland
}

This paper examines the unbundling of research in the context of the Teachers' Research Exchange (T-REX) platform, the national flagship Internet platform in Ireland for teachers to access, use and engage in research. This paper draws on two theoretical frameworks: Laurillard's conversational framework and Salmon's five-stage model. The first highlights the experimental, exploratory and creative aspects of developing an overall framework to structure the digital learning environment for teachers-as-researchers. The second explores the future of higher education and systems like T-REX in the era of digital transformation and the emerging context of Education 4.0. The original contribution is the integration of these frameworks in the creation of an open and shared learning platform so that schools and teachers can be supported to access, collaborate in and undertake research. In particular, the paper outlines signature features of the T-REX design and the way it has emerged over the last 5 years as an innovative platform to mediate the fusion of research and teaching in education. The paper highlights key issues and challenges in unbundling the traditional university, particularly in the context of educational research, but also the imperative of doing so, in the emerging era of Education 4.0.

Implications for practice or policy:

- Supporting teachers' research engagement is increasingly identified as a key priority in the improvement of educational standards and systems.

- T-REX is of value to educationalists interested in a shared learning and open online teacher-research platform.

- There should be a dialogic approach to the relationship between teaching and research, where each informs and enhances the other.

Keywords: Education 4.0, digital transformation, teacher researcher, online research community

\section{Introduction}

Bakhshi et al. (2017) in the research report titled "The Future of Skills Employment in 2030" pointed to the emergence of what Salmon (2019b) has called Industry 4.0 and Employability 4.0, which will mean the redundancy of focusing too much on technical skills, at the expense of life-wide learning (Barnett, 2011), and "the absolute necessity of saying goodbye to disciplinary silos in universities" (Salmon, 2019a, p. 105). There is a need to consider fundamentally what, where and how we are being influenced in our learning in an era of digital transformation and ubiquitous learning. In the current educational ecosystem, involving many of the stakeholders including universities and academics, there are corporate actors challenging the accepted view of what constitutes meaningful and worthwhile knowledge. Innovation in digital learning is 
creating new possibilities for research design and innovation in the area of methodologies, building collaborative, open learning capacity to support universities and academics and education providers. The time seems ripe now to consider how we can unbundle the traditional university, fostering new partnership and ways of working and learning that are both student-centred and enterprise-engaged, and more meaningful for the other sectors within the education system: early childhood, primary, post-primary and adult and continuing education. Indeed, there is a wider imperative to do so; to address the educational, societal and economics challenges we face today and into the future, Salmon (2019a, p. 104) noted how "in higher education we need to move rapidly to Education 4.0".

As described by Salmon (2019a), the evolving and transformative education space has seen the effective use of virtual learning environments in institutes of higher education and school settings (termed Education 2.0), then the recognition of collaborative learning (Education 3.0) to the current emergence of Education 4.0 - the provision of educational platforms mediated by artificial intelligence and machine learning. The European University Association (2016) highlighted "the potential for sharing information has changed research and created opportunities for new ways of collaboration, often referred to as open science or open research" (p. 4). Online digital platforms provide a very powerful suite of tools to undertake research projects. Such platforms harness the power of digital technology and can provide interactive community and usable content for teachers, so they can more easily access and benefit from research collaboration and innovation.

Research internationally has pointed to teacher education being slow to embrace and adapt to the rate of change towards learning and teaching (Goh \& Wong, 2015). The necessity for teaching to be research informed, where research practice is supported, is critical to the development of teacher education and the teacher career trajectory. Educational change and innovation must be evidence-informed and predicated on a robust research base. For teaching to be seen as a valued profession, it needs to be research led (Lofthouse, 2016; MacPhail \& O'Sullivan, 2019). However, the concept of research underpinning practice needs to be valued conceptually and incorporated more evidently in practice. The Teachers' Research Exchange (TREX) platform (http://www.t-rex.ie/) is emerging at an interesting time, within a national context that aims to support teachers' research engagement and the rebundling of research together with teaching; that is, not only is the tertiary level sector currently reframing how it undertakes and shares educational research, schools and teachers are being required to rethink how research and partnership in research might be relevant to them. The focus, therefore, of T-REX is a dialogic approach to the concept of rebundling teaching with research, where each informs and enhances the other: the fusion of research-informed teaching and teaching-informed research.

We begin by describing the setting, policy and rationale pertaining to the development of T-REX. We discuss the key theoretical frameworks that underpin this paper and analyse the platform design and system, sharing methods mapping its key features with the core principles of the frameworks. We also discuss and articulate the lessons learned from this analysis in the context of T-REX; however, the lessons are equally useful for anyone engaged in developing online learning and open research environments.

The aim of this paper is to analyse an online portal developed to support teachers as researchers using two theoretical frameworks to inform our analysis of the shared learning platform. The first identifies a framework to identify and support creative aspects of what a teaching strategy should embody to fulfil higher order thinking and learning, which can be adapted to support teacher-research (Laurillard, 2002). The second framework identifies the future of higher education, in relation to the fourth industrial revolution, termed Education 4.0 (Salmon, 2019a) and the key to active online learning in the form of a five-stage model for e-tivities (Salmon, 2013), which present both principled and practical approaches. The paper examines the T-REX platform, which supports conversations, collaborations and connections between research, policy and practice, in the context of these two frameworks in order to facilitate continued development and enhancement of the educational ambitions of the platform.

\section{Background and context}

A debate in recent years has been the opening up of research to wider audiences and communities in order to bridge the divide between what some refer to as the small but important research taking place in individual classrooms, alongside what might be conceived as the more academic research that is undertaken in the university setting (Strauss, 2016). Therefore, the purpose of open educational resources (OER) has 
been to expand and enhance the impact of research, a central concern of funders and policymakers, particularly where public money is being used to sponsor research. The 2012 OER Paris Declaration stated that OER are "teaching, learning and research materials in any medium, digital or otherwise, that reside in the public domain or have been released under an open license that permits no-cost access, use, adaptation and redistribution by others with no or limited restrictions." (UNESCO, 2012, p.1). OER benefit teachers as they are accessible, affordable and flexible, and the intellectual capital is available on the platform for reuse. Keeping in mind the large number of stakeholders within the education sector, the potential advantages of open education and OER extend beyond educators and materials developers and also benefit policy makers, higher education institutes and their researchers; advancing knowledge by unlocking information for the interest for all. There exist several high-potential blended and virtual systems for open, online educational research, including MESHGuides (http://www.meshguides.org) and the Open Schools for Open Societies portal (https://www.openschools.eu), which are deployed to facilitate collaborative research with teachers, schools and informal educational providers.

Purposefully designed research supports and structures are needed to make this happen; and in the Irish context, a number of initiatives have emerged at a national and system level, to close the gap and promote openness to research in schools and classrooms (Teaching Council, 2018). One of these key initiatives in Ireland is T-REX, a set of blended supports - including a multi-featured website - to promote and support teachers to collaborate in research and utilise research in their classroom practice.

The development of T-REX coincided with government policy recognition of the importance of the role of teachers as researchers. The Teaching Council, the regulatory body of teachers in Ireland, maintains the register of qualified teachers and was established in 2006. At that time, a raft of compliance-focused accountabilities was set in motion in terms of professional standards for teaching and accreditation of all teacher education programmes nationally. The Teaching Council advocates that initial teacher education programmes in Ireland, similar to elsewhere in the Organisation for Economic Co-operation and Development, should be research-based in the sense that pre-service student teachers would both generate and use research in their practice, advocating for teacher-as-researcher (O'Donoghue et al., 2017). The Irish initial teacher education landscape changed significantly following recommendations by an international review panel in 2012 (Sahlberg et al., 2012), where it encouraged strongly that all teacher education was to be research-driven within a university setting (Higher Education Authority, 2019). As detailed in the introduction of the report, the panel was asked:

To identify possible new structures which will recognise and address weaker areas in the system of teacher education; leverage the current strengths in the system; and envision innovative strategies so that Ireland can provide a teacher education regime that is comparable with the best in the world. (Sahlberg et al., 2012, p. 5)

At a time of advancing internationalisation and a transformative higher education sector, the review panel was invited on behalf of the Department of Education and Skills, to bring Ireland in line with other Organisation for Economic Co-operation and Development countries and strongly performing education systems. The report found that in such strong performing education systems "teachers are educated in academic universities where theory and practice are combined to form a foundation for teaching that is on a par with other academic professions" (Sahlberg et al., 2012, p. 5). Aligning to the National Strategy for Higher Education 2030, the report encouraged the enhancement of students' learning by an increased focus on research; with a central role for research in teacher education in all of its teacher education institutions. It encouraged a research-based teacher education programme so teachers are able to utilise educational research as part of their work in school settings and to reflect and develop their own professional development. The report recommended strongly for graduate teachers to be capable of applying research to their work in a constructive and reflective way; and thus leading by example to their students in encouraging learning which is enquiring, engaged and critical (Sahlberg et al., 2012, p. 21). In a follow-up visit in 2019, the panel remarked on how research was becoming a core component in the preparation and education of Ireland's future teaching community and indeed singled out T-REX as a pioneering online social network for teachers and academic researchers (Higher Education Authority, 2019). 


\section{Theoretical framework}

Whilst T-REX is underpinned by a community of practice framework (Wenger et al., 2002), the focus of this paper is to examine the pedagogical credentials of the platform using the conversational framework (Laurillard, 2002) and the five-stage model for online learning (2019a). Both frameworks acknowledge teaching as a design science based on continuous collaborative improvement and adaption in practice (Laurillard, 2013), and the significant potential of digital technology to support teachers' creativity, research and inspiration (Scharmer, 2009).

T-REX emerged in a changing landscape for educational research in Ireland (Sahlberg et al., 2012). There are several, related new developments, which are fostering an enabling context for teachers to access, engage with and even undertake research. Currently, a new national framework has been introduced, which aims to valorise and support teachers becoming involved in research (Teaching Council, 2018). It is called CROÍ (the Irish for "heart") and as its name suggests it aspires to place research at the centre of teaching. T-REX is an important aspect of CROÍ and should be considered in the context of a wider ecosystem of supports for teacher research within the Irish context. Research is now foregrounded in initial teacher education in Ireland. All pre-service teacher preparation programmes must contain a substantive research project and many students across the country now use T-REX to support their research work. A new continuing professional development framework for teacher education in Ireland, COSÁN ("path"), is being implemented, which will include a focus on reflective practice and research. T-REX is offered as a tool to facilitate teachers in engaging in research and to prompt reflective practice. Throughout the teaching community in Ireland, research is assuming a much more important and valued role. Not unlike in medical doctors' professional development, research is really now, it would seem, becoming a core part of a teacher's career, and T-REX provides a dedicated space for student teacher researchers, practising teacher researchers and higher education educational researchers in Ireland to engage with research as part of their lifelong learning journey. Irish universities are also highly ranked internationally, and disciplines and schools of education have been utterly transformed in the last 20 in terms of their increased focus on research, and resultant research throughput, in publications, doctoral supervision to completion and grant applications and awards. In education and teacher education, research may have previously been viewed as a niche activity, undertaken by a very select few research stars, but now it constitutes a core part of the academic life of lecturers and professors right across the field of teacher education. This all sets the scene for potentially transformative change in educational research in Ireland, where a new fusion of research and teaching seems to be coalescing.

Underpinning this sea change in the relationship between research and teaching is the need for a dialogic understanding of how one can enrich and mutually enhance the other. As outlined in the Background and context section, technology has also played a significant role in opening up research and transforming teaching, with the emergence of open access, open science and Education 4.0. A critical and helpful perspective for understanding this systemic change - supported by new technology - is provided in the conversational framework of Laurillard (2002).

\section{Conversational framework}

Laurillard (2002) put forward the conversational framework characterising "learning as shared understanding" (p. 145), with a need to combine different technologies in an integrated fashion, and the outcome of the conversational framework is that it achieves higher learning outcomes. The framework draws on the work of Pask (1976) and Marton (1988) in particular, describing the essential form of the academic teaching and learning process (Marton, 1988; Scott, 2001). A theoretical framework, the conversational framework, delineates what a teaching strategy should encompass and can be used in the design of learning environments. With roots in conversation theory, it is based on the idea that learners should consider the how and why of learning and understanding can be measured by the learner's ability to teach back the topic (Heinze et al., 2007; Scott, 2001).

Underpinning this is the concept that the learning process is complex enough to achieve the aims of academic learning, which must involve at least two participants, operating iteratively and interactively on two levels - practice and discussion - and connecting those two levels by the activities of adaptation and reflection (see Figure 1). The two-level dialogic process is between a teacher and a student. In illustrating the communication process occurring between the teacher and student in advancing student knowledge, the 
framework provides for an open and transparent student-teacher relationship (Heinze et al., 2007). Illustrating the two levels in the learning process, discursive (theory) and experiential (practice) levels connections exist between both levels for both teachers and students (Laurillard, 2008). The two-level dialogic process is between the teacher and student.

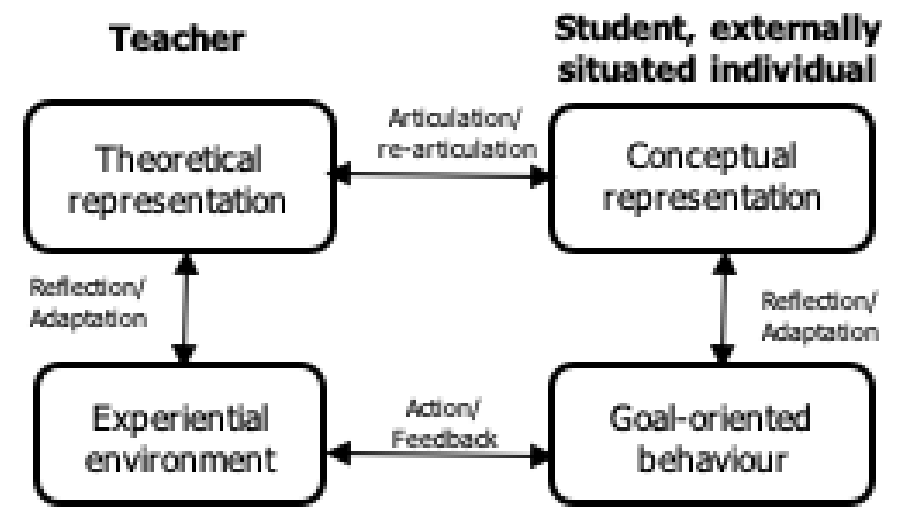

Figure 1. The conversational framework for the learning individual (adapted from Laurillard, 1999, p. 115)

In dialogue with the teacher and reflecting on the experience at the discursive level, the student can articulate the theoretical representation of a particular action in order to generalise and thereby enhance further actions. A goal-action-feedback cycle operates at this level. The underlying goal of the framework achieves congruence between teacher and student, wherein each may achieve a new or deeper understanding. Students are also linked with each other through interactive communication at the discursive level and peer feedback and output comparisons which take place at the experiential level (Laurillard, 2007).

The conversational framework challenges on both a discursive and experiential level and can be used "to help the teaching community rethink their teaching - what is the best way to help their students learn through conventional methods, digital methods or, better, a mix of the two?" (Laurillard, 2008, p. 143). The framework can be used to judge the ability of a new technology to support learning, to critique a learning design (traditional or digital). Thus, it encourages academics to be involved in the design of learning environments and prepare themselves to become reflective practitioners in order to move away from a transmissive teaching approach (Laurillard, 2002, 2008; Laurillard \& McAndrew, 2003).

The technology becomes much more interesting when it is used to give the learner a tool for understanding, not just a fancier form of a book (Laurillard, 2008, p. 16). This framework is key in research-informed teaching provisions as it is widely recognised that learners reach greater levels of understanding when forced to explain and represent knowledge in various different ways and justify their views to others (Brown, 1988; Harel \& Papert; 1990, Hatano \& Inagaki, 1987). The conversational framework is particularly relevant in the context of T-REX. We will presently discuss specific signature features of the T-REX design, in the context of Salmon's (2019a, 2019b) innovative, new partnership as fusion model. However, overall, T-REX embodies the conversational framework. The T-REX platform offers a blend of different tools to enable teachers - many of whom are also in the process of learning how to use and engage in research - to rethink their teaching. At its core, T-REX is a dialogic system, enabling rich conversations between teachers, educational researchers and the wider, professional educational research community. TREX does not support a transmissive model of education, but rather its unique selling point for HE teachers and module leaders is that it facilitates research-practice conversations between students and practising teachers. Previous models of use cited in McGann et al. (2020) outlined how students were partnered with practising teachers and tasks with answering practice-based problems posed by the teacher using research. This required the students to explain and represent their knowledge of the research they had engaged with in various different ways (podcasts, posts, review papers) and justify and explain their views to the teacher through online conversations. The platform has also supported learning conversations between students, between students and lecturers and between students, teachers, lecturers and subject matter experts (see Structure section for details on the T-REX Talks series). 


\section{E-tivities in the five-stage model}

In creating and embedding online teaching and recognising it as a design science based on continuous collaborative improvement and adaption in practice (Laurillard, 2013), the five-stage model of teaching and learning online along with the e-tivity framework presented by Salmon (2013) proposed a structure to ensure relevance, authenticity and usefulness in online learning.

Each of the five stages combine e-moderative with technical support components in creating the learning environment. Stage 1 is concerned with access and motivation, where the learner must engage intermittently and regularly with the online learning platform and commit to the community to ensure full participation and engagement. Stage 2, Online Socialization, encourages the learners to establish an online identity and interact with others. It is at this stage that the learner will understand the benefits, constraints and requirements of working with others in a computer mediated environment. In Stage 3, the learners engage in the sharing of information and contribute to each other's learning. This stage is referred to as information exchange and community cooperation occurs whereby each person supports their colleague's learning goals. Stage 4, Knowledge Construction, occurs when the community discussion and activities develop and the interaction becomes collaborative, more team-oriented and somewhat more complex. The pinnacle Stage 5, Development, is when the learners become responsible for their own learning and develop an ability to exploit fully the benefits for their learning. It is at this stage participants will gain self-insight, reflection and judgements about their learning and knowledge.

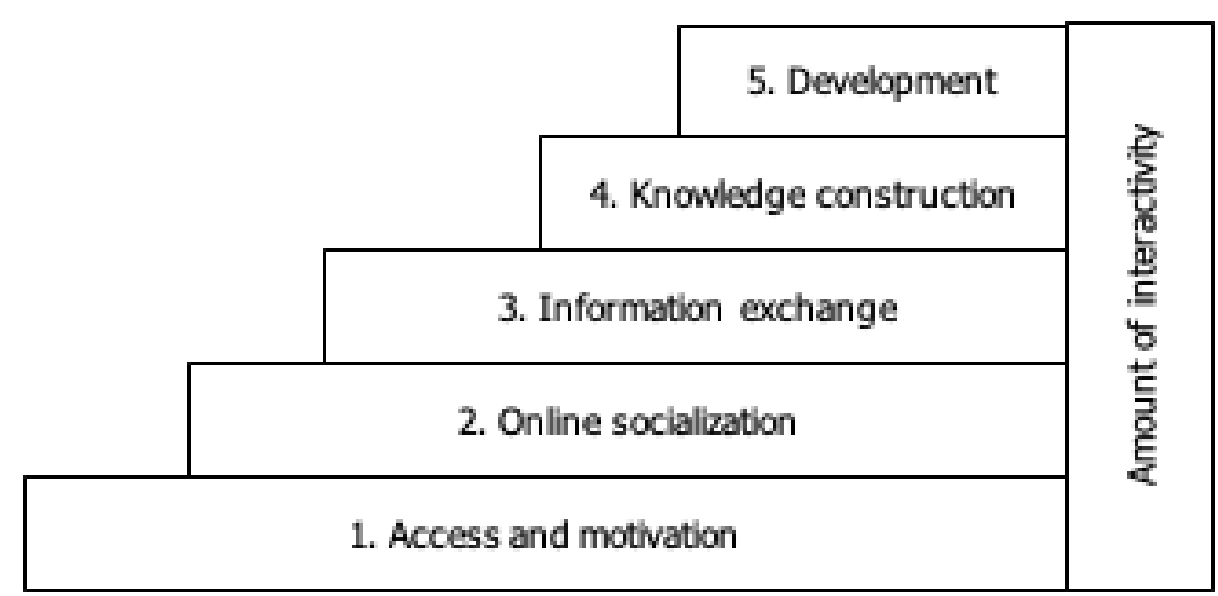

Figure 2. The Five-stage model of teaching and learning online (adapted from Salmon, 2002, p. 11)

The T-REX platform invites teacher-researchers to step through each of the five stages. The opening webpage invites the learner to connect and engage with the platform. The users receive email notifications when messages are posted in the public and private groups they have registered with. T-REX encourages the user to create an online identity by creating a profile, attaching an image of themselves. The activities developed on the platform encourage communication and remote collaboration facilitating the students' online learning experience.

Good design processes result in explicit and high-quality activity by participants in the formation of knowledge, and in order to examine the extent to which T-REX can be used as a pedagogical tool, we have attempted to map the e-tivity framework (Salmon 2013) with an example of a potential T-REX embedded module. The original e-tivity framework presented in Table 1 by Salmon (2013) provides a structure to align with; Table 2 presents an adapted form to be used in a module on the teacher researcher online environment T-REX. 
Table 1

E-tivity framework: how to create an invitation (adapted from Salmon, 2013, p. 3)

\begin{tabular}{|c|c|}
\hline $\begin{array}{l}\text { Number, pacing and } \\
\text { sequencing }\end{array}$ & Number as follows: week, sequence of task \\
\hline Title & $\begin{array}{l}\text { Enticement to open the invitation to take part } \\
\text { Very brief descriptor } \\
\text { Be inventive and creative but keep it very short. }\end{array}$ \\
\hline Purpose & $\begin{array}{l}\text { Explain, if you complete this activity, you will be able to... } \\
\text { You will understand better how to ... } \\
\text { You will find it essential for assignment X } \\
\text { Use verbs } \\
\text { Link directly with your outcomes and or objective for the unit, module, } \\
\text { course and programme. }\end{array}$ \\
\hline Brief & $\begin{array}{l}\text { If you find you have more than one major activity or question, divide into } \\
\text { more e-tivities. } \\
\text { Clear, brief instruction on how to take part and what to do } \\
\text { One question or task per message } \\
\text { When you have written their part, check that the task is self-contained. }\end{array}$ \\
\hline Spark & $\begin{array}{l}\text { Spark to light the fire for the topic, interesting little intervention } \\
\text { Directly link with topic for this week } \\
\text { Opportunity to expose 'content' but with the purpose of a spark to start a } \\
\text { dialogue with others. }\end{array}$ \\
\hline $\begin{array}{l}\text { Individual } \\
\text { contribution }\end{array}$ & $\begin{array}{l}\text { Give clean instructions to the individual participant as to what he or she } \\
\text { should do in response to the spark. } \\
\text { Specify exactly what you are expecting the participant to do and in what } \\
\text { media and by when. Tell them the length of contribution expected } \\
\text { Create a ling from this part of the invitation to the location for posting. }\end{array}$ \\
\hline Dialogue begins & $\begin{array}{l}\text { Request response from an individual to others, what kind of response, how } \\
\text { long, where and by when. } \\
\text { Key point students come online to see if others have read and responded. } \\
\text { Make this happen. } \\
\text { Create a link from their part of the invitation to the location for posting the } \\
\text { response to others. }\end{array}$ \\
\hline $\begin{array}{l}\text { E-moderator } \\
\text { interventions }\end{array}$ & $\begin{array}{l}\text { Clearly indicate what the e-moderator will do and when. } \\
\text { Explain that the e-moderator will summarise, give feedback and teaching } \\
\text { points and close the e-tivity and when this will happen. }\end{array}$ \\
\hline Schedule and time & $\begin{array}{l}\text { Total calendar/elapsed time allowed for the e-tivity. } \\
\text { Completion date } \\
\text { Estimate total study time required }\end{array}$ \\
\hline Next & $\begin{array}{l}\text { Link to next e-tivitiy } \\
\text { You can suggest additional resources to help with the task - indicated } \\
\text { whether they are quired or optional, place the links at the end of the } \\
\text { invitation. }\end{array}$ \\
\hline
\end{tabular}


Table 2

E-tivity framework exemplar for a T-REX embedded module

\begin{tabular}{|c|c|}
\hline $\begin{array}{l}\text { Number, pacing and } \\
\text { sequencing }\end{array}$ & Number as follows: week, sequence of task \\
\hline Title & Let's find our research question. \\
\hline Purpose & $\begin{array}{l}\text { This e-tivity will help you with the practitioner-based research module. } \\
\text { You will find it essential in creating a research question for your future } \\
\text { action research project }\end{array}$ \\
\hline Brief & $\begin{array}{l}\text { Taking part in this course has brought you to a new place - you have new } \\
\text { learning, knowledge and capability now. } \\
\text { To make the most of it here is an e-tivity to encourage you to consider } \\
\text { your trajectory in teacher and offer encouragement to your classmates. }\end{array}$ \\
\hline Spark & $\begin{array}{l}\text { Reflect on the journey of school placement, your lesson plan and weekly } \\
\text { reflections in your online folder. } \\
\text { Revisit the SP tutor feedback and the plenary workshops. } \\
\text { Pick one key posting or comment you made which you feel represents } \\
\text { something that you did not fully understand prior to the tutor pointing it } \\
\text { out to you, a challenge you faces in the classroom or a topic you wish to } \\
\text { further develop more. } \\
\text { Choose carefully. }\end{array}$ \\
\hline $\begin{array}{l}1^{\text {st }} \text { Individual } \\
\text { contribution }\end{array}$ & $\begin{array}{l}\text { Re-post the comment (max. } 100 \text { words) into the T-REX private class } \\
\text { group < link }>\text { with an open source image that represents what you think } \\
\text { about learning it. }\end{array}$ \\
\hline Dialogue begins & $\begin{array}{l}\text { Take a look through the postings and images from your class group. } \\
\text { Where you feel the same and where did you feel differently? } \\
\text { Make a short constructive and supportive suggestion on how your fellow } \\
\text { pre-service teachers might take his/her knowledge forward. } \\
\text { This might be another course of learning, further actions, a note to a } \\
\text { resource or direct offer of an online meeting to discuss or apply their new } \\
\text { knowledge in the future. } \\
\text { Complete by }<\text { date }>\end{array}$ \\
\hline $\begin{array}{l}\text { 2nd Individual } \\
\text { contribution }\end{array}$ & $\begin{array}{l}\text { Between }<\text { date }>\text { and }<\text { date }>\text { (allow } 2 \text { or } 3 \text { days) to undertake one posting, } \\
\text { commit to actually doing something with the new knowledge you first } \\
\text { mentioned. }\end{array}$ \\
\hline E-moderator intervention & $\begin{array}{l}\text { I will comment also on all class postings to ensure equitable feedback to } \\
\text { all students. }\end{array}$ \\
\hline Schedule and time & $\begin{array}{l}\text { Takes about } 2.5 \text { hours in total over a week during Semester } 1 \\
\text { Works well as part of a series of revision e-tivities or where you are } \\
\text { including reflection on assignments. }\end{array}$ \\
\hline Next & Link to next e-tivity \\
\hline
\end{tabular}

\section{Development and fusion of the platform}

Introduced in 2015, T-REX has scaled from a small-scale innovate platform to a nationally funded initiative. It now forms an integral element in a vast educational ecosystem to support teachers as researchers in Ireland. A key focus of T-REX is to act as a bridge between so-called small $r$ research taking place in individual classrooms, and big $r$ research that is undertaken in formal, funded contexts, e.g. thirdlevel colleges and universities. Key policy changes have helped significantly to mobilise the current infrastructuring at a national level to enable the teacher researcher community as detailed previously. In the work by Salmon (2013), the e-tivity framework proposed nine categories outlining the route for inviting connectedness in online learning. Subsequently, Salmon (2019b) presented on developing partnerships referring to the metaphor of infection. The work referred to an online learning community bringing protection as well as increased well-being, which very much aligns to the aims of T-REX. The following section introduces T-REX with regard to prototype, pedagogy, resources, trust, capability and structure. 


\section{Prototype}

The project was first conceptualised in 2015, then titled REX (Research Expertise Exchange) an online social network for Irish teachers and other educational researchers (McGann et al., 2020). REX was funded by the National Forum for the Enhancement of Teaching and Learning in Higher Education, a body responsible for leading and advising on teaching and learning in Irish higher education.

In 2019, the project rebranded as T-REX - the Teachers' Research Exchange - following receipt of funding and support from Research Alive! a consortium of the Teaching Council, National Council for Curriculum and Assessment and Centre for Effective Services. The Research Alive! consortium sought to grow the teacher membership and use of the platform and embed the platform within the broader landscape for teacher professional development.

The National Forum for the Enhancement of Teaching and Learning in Higher Education also continues to support the project to further develop T-REX as a teaching and learning tool in higher education and enhancing the reach, scope and sustainability of the project. The number of participant universities is expanding to include additional partner organisations as well as teachers' professionals from across the country.

\section{Pedagogy}

Salmon (2019b) referred to the change in university from one which handed-over content to be digitised, to the newer approach of jointly the framing, designing and engaging approach where academics ensure full engagement for all contributors. The intelligence and expertise in online pedagogy is what concerns the activity on the platform. Pedagogical intelligence refers to the complex and dynamic relations between teaching and learning (Salmon, 2013) and therefore of importance to the quality of online community activity ensuring the platform is fit for purpose.

The T-REX module innovation framework is an example of this pedagogical supportive structure whereby the platform engages the pre-service teachers in their initial teacher education setting. The T-REX module innovation framework (now in its second round of funding) is a competitive scheme where module leaders and innovators in teacher education in the third-level colleges and universities can apply for support to embed the T-REX philosophy and technology within their teacher education modules. The successful applicants receive pedagogical and technological support, as well as funding, to embed T-REX systemically in their modules. The modules awarded to date included research project specific modules, but also modules on inclusive education, maths education, educational psychology and language and literacy, therefore accommodating a variety of topics.

The module innovation framework has been a valuable aspect of the project development as it helps to directly mobilise the initial teacher education research community engage with T-REX. Teacher continuing professional development is a continuum, and engaging with pre-service teachers constitutes a core aspect of promoting research engagement as they form their teacher identities, prior to embarking on their professional teaching career as lifelong learners and as lifelong researchers.

\section{Resources}

The key in balancing partner resources and capabilities with activities and outcomes to be achieved in the scope of the portal is another of the suggestions in the framework proposed by Salmon (2019b). T-REX accommodates this in the generation of T-REX Bytes - providing teachers with a visually appealing and easy-to-read and navigate précis of a research project, research data or methodological approach. Teachers, educators and researchers can create and upload their own T-REX Bytes, using the easy-to-complete online pro forma for generating a summary of research. They can also enhance their T-REX Bytes with multimedia, images and video, where this is available.

The provision of research digests for teachers and researchers has emerged as a key activity in terms of promotion of research in schools. For example, developed by the Education Futures Collaboration in the United Kingdom, MESHGuides (http://www.meshguides.org) provide teachers with summaries of research 
on key issues, themes and topics for the classroom; Cambridge Mathematics provide Cambridge Espressos - filtered research on mathematics education (http://www.cambridgemaths.org/espresso/).

Further resources in development for T-REX include T-REX Bitesize Courses and the T-REX Research Directory. The Bitesize courses will focus on developing teachers' confidence and competency to engage with and undertake research. The first two courses will be primers and address identified key priorities for teachers and other educational researchers - Getting into research and the second, Sharing your research - as many may be engaging with research for the first time. Modelled on the European Union's repository, CORDIS (https://cordis.europa.eu), the T-REX Research Directory (RD) will contain hyperlinked details of active and archive research projects. T-REX users will also be able to add their projects to the RD. It will thus serve as a first national database of educational research projects in Ireland.

\section{Trust}

We know that involving emotions in online learning and computer mediated communication helps promote reflectiveness (Moon, 2006). Webs of trust that do not depend on physical meeting are essential in an online platform, and building trust amongst participants and the community is crucial. Having a shared community of practice with shared goals and values is critical to the success of T-REX; therefore, embedding engagement between participants and purposeful e-learning activities builds a sustainable community of active teacher researchers.

T-REX is a teacher researcher platform connecting the three main constituencies of educational partners in Ireland: pre-service teachers; higher education educational researchers; and in-service teachers/practitioners. Salmon $(2019 \mathrm{~b}, \boldsymbol{\Phi} 11)$ referred to how "effectiveness is about applying the needed effort at the correct distance along the lever". The many partners involved in and supporting T-REX on the trajectory are committed to its success as to fulfil national priority objectives for teacher education and teacher continuing professional development.

As well as a social networking-style interface to support connection and collaboration with other educators and researchers, T-REX offers teachers a number of bespoke supports for engaging with, and in, research (McGann et al., 2020). The ideas for these innovations have emerged through the T-REX leadership and design team's extensive consultation along a number of contexts: systematic literature review; user-centred design, (e.g., Thinking Aloud Protocol to test features with users); review of similar extant technologies; and, crucially, engagement with key educational stakeholders and partners. We now outline highlights of these bespoke design features of the T-REX platform.

The design of a digital bridge to connect communities and build trust is a signature feature of the T-REX design. The user landing page for the site includes a number of additional dynamic features to enhance the community, including recent activity; upcoming events; and a live, updated feed of relevant news items about education, in Ireland and internationally. Users can also create and join different projects and special interest groups (SIGs), which are emerging and coalescing around important educational research themes, initiatives, trends and projects (McGann et al., 2020).

Upon registration on the site (http://www.t-rex.ie), all T-REX users can log in to the system and develop a profile, including a pen picture, research interests, sector and biographical details. Linking and connecting with other users around cognate and shared research foci and interests is easily achieved, where a living conversation on educational research is mediated by the technology. T-REX seeks to establish an active, vibrant community of people interested in generating and using educational research. The emphasis is on communication and sharing among all the participating professionals.

\section{Capability}

Salmon (2019a) referred to the concept of capability in terms of the people who have the capability to operation across organisation and roles. The champions of the T-REX platform are the funding body Research Alive! (Teaching Council, National Council for Curriculum and Assessment and Centre for Effective Services, https://ncca.ie/en/about/collaborations-and-partnerships/molfeasa-research-alive), the T-REX module innovation framework recipients as well as the T-REX team of researchers and developers in each of the constituent institutes of higher education. 
To further add to the capability of the core team, T-REX encourages additional expert academic research input, designed to engage teachers with recognised leaders in various fields of educational research internationally. T-REX Talks (https://www.t-rex.ie/rexperts/) is a series of expert academic research inputs, designed to engage teachers with recognised leaders in various fields of educational research internationally. Leading international experts in key topical areas of research are invited to provide an online chat. During a T-REXpert chat, teachers can join the discussion, ask questions and develop their understanding of key concepts and principles in hot topics in international educational research. For example, in March 2019, Professor Susan McKenney, University of Twente, The Netherlands, conducted a T-REXpert chat using the T-REX platform, to engage in a discussion of educational design research. Educational design research is a high-potential research methodology which has been emerging and growing in popularity in recent years, and particularly given the continuing interest in technological innovation in education over the last 25 years. An Educational Design Research SIG was formed on TREX, which enabled teachers, educational researchers and the expert to share papers and ideas, and engage in focused discussion on key issues and the possibilities of educational design research in classrooms and schools today. Other such focus T-REX Talks have been conducted on inclusive education and special education needs with similar eminent experts.

\section{Structure}

The research process is best manifested as a two-way interaction rather than a one-way dissemination of research where teachers are considered partners in the research process rather than as consumers. Academic researchers and teachers may have distinct roles within the research process though these roles may be interchangeable. This helps to address the challenges of inclusivity and diversity and ensure a dialogical character to the newly developing domain that respects the already existing communities of practice within the various professions.

The manner in which both student teachers and practising teachers can collaborate within T-REX illustrates the role in can play in unbundling the scaffolding of some aspects of initial teacher education into the professional teaching context. Teachers leading research questions unsettles the older models where research is the domain of the higher education sector alone, while also helping student teachers better perceive the continuity between their time in college with their continuous learning journey over the course of their career.

The hierarchy of operational roles and teams, from project oversight to individual SIG participation the platform design, was informed by the principles of Wenger et al. (2002) and Salmon (2019a), in helping structure the development of the platform and community. T-REX recognises that academic researchers, student researchers, and teachers all have essential roles to play in the generation and use of research. For example, as T-REX has evolved, the Teaching Council aim to host support groups for those teachers benefiting from their Research Support Framework, a fund dispersed with the intention of encouraging research engagement amongst working teachers in Ireland (Teaching Council, 2018).

To enable the formation and initial recruitment of interested members for such groups, SIGs on T-REX have been seeded using online communication with research leaders in the area. Some discussions, termed T-REXpert chats, are text-based conversations in which the research leader provides short answers to member-posted questions, which provide the stimulus for further participant conversations. These conversations also offer opportunities for clarificatory dialogue between academic researchers and practising teachers, to help overcome the challenges of technical vocabularies and differences of professional dialects. Figure 3 illustrates the T-REX Educational Design Research SIG where collaborative discussion and interaction take place. 


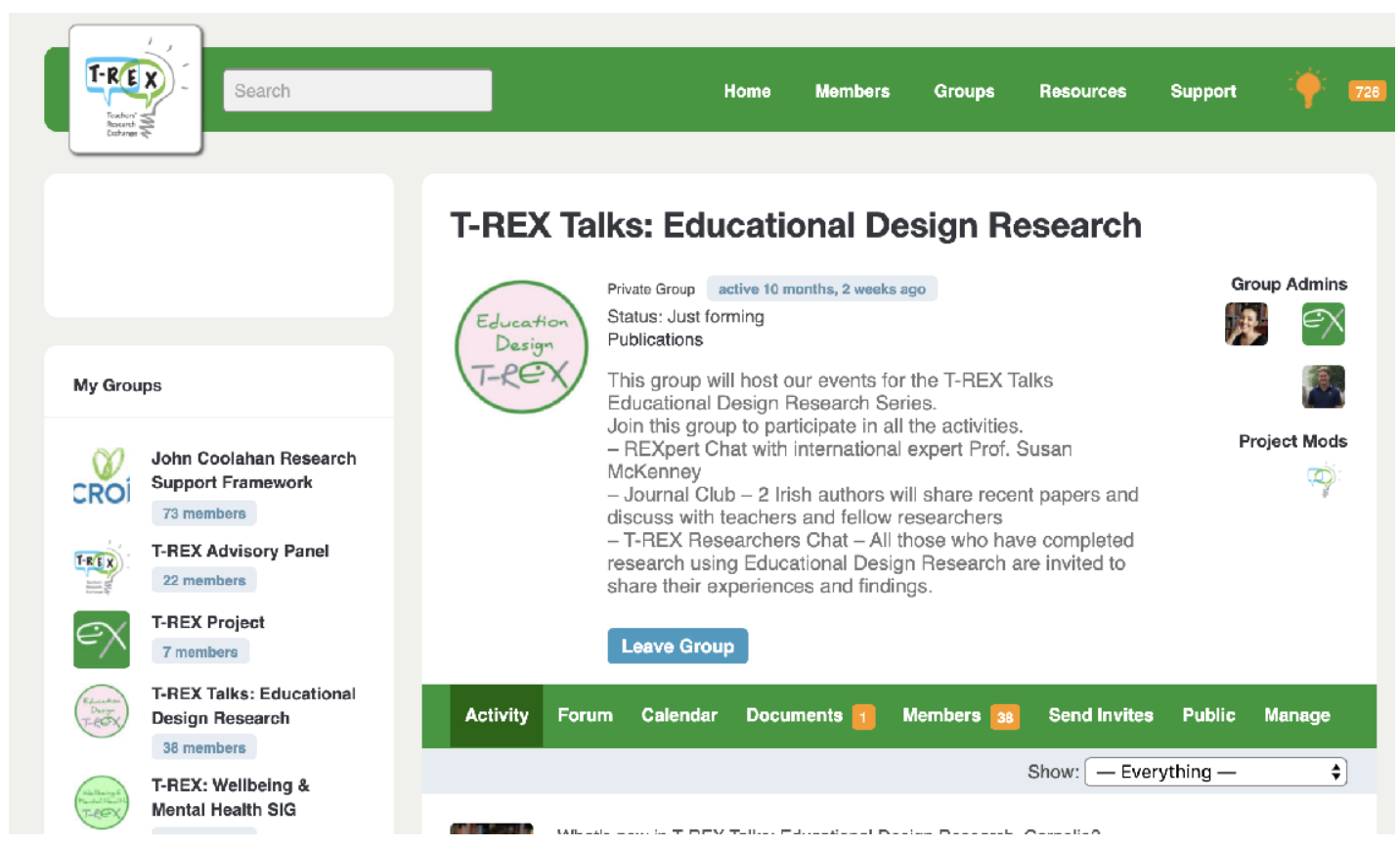

Figure 3. The T-REX Education Design Research SIG page

\section{Conclusion}

In this paper, we have identified the main signature features of the T-REX design, situated in the context of Laurillard's (2002) overarching conversational framework, and the salient, specific aspects of Salmon's (2019a) fusion model of partnership. T-REX is centrally concerned with trying to achieve scale in its impact with Irish teachers and educational researchers, as are the related developments taking place in the wider system, principally CROÍ. In recent discussions about achieving scale in the design of educational innovation, Penuel (2019) suggested that we need a wider perspective for how transformative change can be achieved in education, what he called infrastructuring. Infrastructuring - as the name suggests - entails supporting innovation through a sustainable and lasting, multi-stakeholder infrastructure where there is equitable partnership between the key educational players, located at all the relevant levels in the educational system. Simply put, in order to embed and sustain educational innovation systematically, transformation should be attempted in an inclusive way that involves everyone that needs to be involved to make the change happen, and in a context that supports them to achieve it.

In Ireland at the moment, one can feel optimistic that perhaps the system is at a tipping point in terms of the wider infrastructure for teachers to be involved meaningfully and productively in research. T-REX is designed to be a driver of transformation in how Ireland's educational professionals and teachers engage collaboratively, both in and with research. Evidenced by the 3000 users registered as of March 2020, TREX is scaling as a national online platform.

The conversational framework and fusion model of partnership illustrate how the multiple bespoke features of the T-REX system afford significant scope for teachers to become involved in research and share productively in consequential research conversations and collaborations. This is enabling T-REX to achieve impact, and it is poised to continue to do so. However, viewing the kind of change at system level that is sought in Ireland through the perspective of infrastructuring, T-REX will likely to succeed only if the other innovations in the wider context, for example, CROÍ, also sustain and grow. There are multiple dependent variables involved in the change that is needed in how research is conceptualised and undertaken in the Irish educational system. That broader context - as it changes now - has the potential to bring the divergent and diverse research and teaching communities more closely together, for their mutual benefit; and T-REX forms a crucially important, constituent part of the change ecosystem. Although developed in the context of a national framework for educational change - as the Irish educational system evolves towards Education 4.0 - T-REX provides an exemplar for how an online teacher researcher community can be designed, to 
support a fusion of research-informed teaching and teaching-informed research. T-REX, its distinctive design and features, serve as a prototype model for how digital transformation can be applied to the important educational goal of creating a dynamic, shared community of teacher researchers.

\section{Acknowledgements}

The authors acknowledge our educational partners, without whom T-REX would simply not be possible. Firstly, our funders: The Teaching Council, National Council for Curriculum and Assessment, Centre for Effective Services, and the National Forum for the Enhancement of Teaching and Learning in Higher Education, for their continued and renewed support, commitment and contributions to making T-REX thus far successful. We also thank our Advisory Panel and our colleagues in the respective universities.

\section{References}

Bakhshi, H., Downing, J. M., Osborne, M. A., \& Schneider, P. (2017). The future of skills: Employment in 2030. Pearson. https://futureskills.pearson.com/research/assets/pdfs/technical-report.pdf

Barnett, R. (2011). Lifewide education: A transformative concept for higher education. In N. Jackson (Ed), Learning for a complex world (pp. 22-38). Authorhouse. http://www.lifewideeducation.uk/uploads/1/3/5/4/13542890/learning for a complex world.pdf\#page $=58$

Brown, A. L. (1988). Motivation to learn and understand: On taking charge of one's own learning. Cognition and Instruction, 5(4), 311-321. https://doi.org/10.1207/s1532690xci0504 4

European University Association. (2016). Doctoral education-taking Salzburg forward: Implementation and new challenges. https://www.eua-cde.org/downloads/publications/2016 euacde doctoralsalzburg-implementation-new-challenges.pdf

Goh, P. S. C., \& Wong, K. T. (2015). Exploring the challenges for teacher educators. Journal of Research, Policy \& Practice of Teachers and Teacher Education, 5(1), 37-45. http://202.45.132.61/index.php/JRPPTTE/article/view/197

Harel, I., \& Papert, S. (1990). Software design as a learning environment. Interactive Learning Environments, 1(1), 1-35. https://doi.org/10.1080/1049482900010102

Hatano, G., \& Inagaki, K. (1987). A theory of motivation for comprehension and its application to mathematics instruction. In T. A. Romberg \& D. M. Steward (Eds.), The monitoring of school mathematics. Background Papers. (Vol. 2.): Implications from psychology, outcomes from instruction (pp. 27-46). Wisconsin Center for Educational Research.

Higher Education Authority. (2019). The structure of teacher education in Ireland: Review of progress in implementing reform. https:/hea.ie/assets/uploads/2019/05/HEA-Structure-of-Teacher-Education.pdf

Heinze, A., Procter, C., \& Scott, B. (2007). Use of conversation theory to underpin blended learning. International Journal of Teaching and Case Studies, 1(2), 108-120. https://doi.org/10.1504/IJTCS.2007.014213

Laurillard, D. (1999). A conversational framework for individual learning applied to the 'learning organisation' and the 'learning society'. Systems Research and Behavioral Science: The Official Journal of the International Federation for Systems Research, 16(2), 113-122. https://doi.org/10.1002/(SICI)1099-1743(199903/04)16:2<113::AID-SRES279>3.0.CO;2-C

Laurillard, D. (2002). Rethinking teaching for the knowledge society. EDUCAUSE Review, 37(1), 16-35. https://er.educause.edu/articles/2002/1/rethinking-teaching-for-the-knowledge-society

Laurillard, D. (2007). Pedagogical forms for mobile learning: framing research questions. In N. Pachler (Ed.), Mobile learning: Towards a research agenda (pp. 153-175). University of London. https://discovery.ucl.ac.uk/id/eprint/1569055/1/mobilelearning_pachler_2007.pdf

Laurillard, D. (2008). The teacher as action researcher: Using technology to capture pedagogic form. Studies in Higher Education, 33(2), 139-154. https://doi.org/10.1080/03075070801915908

Laurillard, D. (2013). Teaching as a design science: Building pedagogical patterns for learning and technology. Routledge.

Laurillard, D., \& McAndrew, P. (2003). Reusable educational software: A basis for generic learning activities. In A. Littlejohn (Ed.), Reusing online resources: A sustainable approach to e-learning (pp. 81-93). Kogan Page. 
Lofthouse, R. M. (2016). Best practices in mentoring for teacher and leader development. International Journal of Mentoring and Coaching in Education, 5(2), 158-159. https://doi.org/10.1108/IJMCE-032016-0020

MacPhail, A., \& O'Sullivan, M. (2019). Challenges for Irish teacher educators in being active users and producers of research. European Journal of Teacher Education, 42(4), 492-506. https://doi.org/10.1080/02619768.2019.1641486

Marton, F. (1988). Describing and improving learning. In R. R. Schmeck (Ed.), Learning strategies and learning styles (pp. 53-82) Springer. https://doi.org/10.1007/978-1-4899-2118-5 3

McGann, M., Ryan, M., McMahon, J., \& Hall, T. (2020). T-REX: The teachers' research exchange. Overcoming the research-practice gap in education. TechTrends, 64, 470-483. https://doi.org/10.1007/s11528-020-00486-4

Moon, J. A. (2006). Learning journals: A handbook for reflective practice and professional development. Routledge. https://doi.org/10.4324/9780203969212

O’Donoghue, T., Harford, J., \& O’Doherty, T. (2017). Teacher preparation in Ireland: History, policy and future directions. Emerald Group Publishing. https://doi.org/10.1108/9781787145115

Pask, G. (1976). Styles and strategies of learning. British Journal of Educational Psychology, 46(2), 128148. https://doi.org/10.1111/j.2044-8279.1976.tb02305.x

Penuel, W. (2019). Infrastructuring as a practice of design-based research for supporting and studying equitable implementation and sustainability of innovations. Journal of the Learning Sciences, 28(5), 659-677. https://doi.org/10.1080/10508406.2018.1552151

Sahlberg, P., Furlong, J., \& Munn, P. (2012). Report of the international review panel on the structure of initial teacher education in Ireland. Department of Education and Skills. https://www.education.ie/en/Publications/Education-Reports/Report-of-the-International-ReviewPanel-on-the-Structure-of-Initial-Teacher-Education-Provision-in-Ireland.pdf

Salmon, G. (2002). E-tivities: The key to active online learning. Kogan Page.

Salmon, G. (2013). E-tivities: The key to active online learning. (2nd ed.) Routledge.

Salmon, G. (2019a). May the fourth be with you: Creating education 4.0. Journal of Learning for Development, 6(2), 95-115. https://j14d.org/index.php/ej14d/article/view/352

Salmon, G. (2019b, February 1). From partnership to fusion: Future educational landscapes. Wonkhe. https://wonkhe.com/blogs/from-partnership-to-fusion-future-educational-landscapes/

Scharmer, C. O. (2009). Theory U: Learning from the future as it emerges. Berrett-Koehler Publishers.

Scott, B. (2001). Gordon Pask's conversation theory: A domain independent constructivist model of human knowing. Foundations of Science, 6, 343-360. https://doi.org/10.1023/A:1011667022540

Strauss, V. (2016, May 10). 'Big data' was supposed to fix education. It didn't. It's time for 'small data.' The Washington Post. https://www.washingtonpost.com/news/answer-sheet/wp/2016/05/09/big-datawas-supposed-to-fix-education-it-didnt-its-time-for-small-data/

Teaching Council. (2018), Teaching Council Strategic Plan 2018-2020, https://www.teachingcouncil.ie/en/Publications/Strategic-Plan/Teaching-Council-Strategic-Plan-20182020.pdf

UNESCO. (2012). 2012 Paris OER Declaration. http://www.unesco.org/new/fileadmin/MULTIMEDIA/HQ/CI/CI/pdf/Events/English_Paris_OER_De claration.pdf

Wenger, E., McDermott, R. A., \& Snyder, W. (2002). Cultivating communities of practice: A guide to managing knowledge. Harvard Business Press.

Corresponding author: Cornelia Connolly, cornelia.connolly@nuigalway.ie

Copyright: Articles published in the Australasian Journal of Educational Technology (AJET) are available under Creative Commons Attribution Non-Commercial No Derivatives Licence (CC BY-NC-ND 4.0). Authors retain copyright in their work and grant AJET right of first publication under CC BY-NC-ND 4.0.

Please cite as: Connolly, C., Hall, T., Ryan, M., McMahon, J., McGann, M., \& Egan, A. (2021). A fusion of research-informed teaching and teaching-informed research: Designing a scalable online ecosystem for new partnerships in educational research. Australasian Journal of Educational Technology, 37(1), 82-95. https://doi.org/10.14742/ajet.6131 